\title{
Bur open \\ A public opinion survey: is presumed consent the answer to kidney shortage in Hong Kong?
}

\author{
Tak Kwong Chan, ${ }^{1}$ Benjamin John Cowling, ${ }^{2}$ George Lim Tipoe ${ }^{1}$
}

To cite: Chan TK,

Cowling BJ, Tipoe GL. A public opinion survey: is presumed consent the answer to kidney shortage in Hong Kong?. BMJ Open 2013:3:e002013.

doi:10.1136/bmjopen-2012002013

- Prepublication history and additional material for this paper are available online. To view these files please visit the journal online (http://dx.doi.org/10.1136/ bmjopen-2012-002013).

Received 24 August 2012 Revised 19 November 2012 Accepted 20 November 2012

This final article is available for use under the terms of the Creative Commons Attribution Non-Commercial 2.0 Licence; see http://bmjopen.bmj.com

\begin{abstract}
${ }^{1}$ Department of Anatomy, University of Hong Kong, Hong Kong, Hong Kong ${ }^{2}$ Department of Community Medicine, School of Public Health, University of Hong Kong, Pokfulam, Hong Kong
\end{abstract}

Correspondence to Dr Tak Kwong Chan; theo@hku.hk

\begin{abstract}
Objective: To project the impact of an opt-out system (presuming consent) in Hong Kong on the likelihood that a potential donor donates his or her kidneys after death and the likelihood of violating a potential donor's autonomy.
\end{abstract}

Setting: Cross-sectional population-based anonymous telephone survey.

Participants: Random sample of 802 adults aged between 18 and 64 .

Main outcome measure: Willingness to donate their own kidneys after death and their willingness to donate the kidneys of a deceased family member in different hypothetical situations under the current opt-in system and under our proposed soft version of an opt-out system.

Results: When the wish of the deceased is unknown, $72.6 \%(n=583)$ of the respondents said that under the proposed opt-out system, they would definitely or likely consent to donating the kidneys of a deceased family member, significantly more than under the current optin system (OR 2.53, 95\% Cl 2.06 to 3.11). An opt-out system could significantly improve the projected overall donation potential from 0.631 to 0.771 (OR $1.97,95 \%$ $\mathrm{Cl} 1.58-2.45$ ) and reduce the projected overall chance of violating the autonomy of a potential donor from 0.292 to 0.127 (OR $0.35,95 \% \mathrm{Cl} 0.27$ to 0.45 ).

Conclusions: A switch to an opt-out system in Hong Kong would likely result in the wishes of more people being followed and raise the overall cadaveric kidney donation rate.

\section{INTRODUCTION}

At the end of the year 2011, more than 7000 people in Hong Kong were suffering from end-stage renal failure and 1781 people were on the waiting list for a kidney transplant. But there were only 59 cases of cadaveric kidney transplant in 2011, equivalent to 8.34 donations/million population. In other words, we are facing shortage of kidneys in Hong Kong as in many other parts of the world.

Hong Kong currently has an explicit consent system that requires individuals to opt in to allow their kidneys to be used after

\section{ARTICLE SUMMARY}

\section{Article focus}

- To project the impact of an opt-out system (presuming consent) in Hong Kong on the likelihood that a potential donor donates his or her kidneys after death.

- To project the impact of an opt-out system (presuming consent) in Hong Kong on the likelihood of violating a potential donor's autonomy.

Key message

- An opt-out system could significantly improve the projected overall donation potential from 0.631 to 0.771 (OR $1.97,95 \% \mathrm{Cl} 1.58$ to 2.45 ) and reduce the projected overall chance of violating the autonomy of a potential donor from 0.292 to 0.127 (OR $0.35,95 \% \mathrm{Cl} 0.27$ to 0.45 ).

Strengths and limitations of this study

- In light of the hesitation to switch to an opt-out system, the study may be useful with a view to refuting the speculative claim that an opt-out system has the potential to impact negatively on the donation rate and patients' autonomy.

- The projection on the donation potential and chance of violating one's autonomy was based on self-reported preferences and intentions. There may be overestimation or underestimation.

death by signing a donor card or signing up on the central organ donation register (CODR) online, by post or by fax. Permission from the family is necessary if a potential donor has not registered a wish to donate the kidneys before death. Even if an individual has a donor card or has joined the CODR, it is common practice in Hong Kong to speak to the family if possible.

In other words, our current practice assumes that, when one dies, he or she is among the minority who do not wish to donate unless he or she has opted in. We hypothesise that by changing the default position to presumed consent-assuming people want to donate unless they opt out-we could help save more lives while respecting the wishes of those who 
wish to donate and protecting the rights of those who do not. We propose a soft version of opt-out policy that would continue to involve the family. Even if an individual has not opted out, the family would be asked whether they are aware that the person has any unregistered objection. We would not proceed if the answer is yes. The organs would not be used in case the family raise objection even if the answer is no.

Notwithstanding a number of studies showing that countries that implement an opt-out policy had higher donation rates than those that do not, ${ }^{1}{ }^{2}$ opponents argued that a strategy working in one society might not work in another, ${ }^{3}$ due to the variations in legislation, availability of donors and infrastructure of the transplantation service in different countries. ${ }^{4}$ Critics have also expressed concerns that to presume consent would strip people of the right to make their own choice undermining their autonomy. ${ }^{5}$ In the circumstances, we conducted a survey of a representative sample of individuals in Hong Kong to estimate whether an opt-out system would increase the likelihood that a potential donor donates his or her kidneys after death and whether it would increase the likelihood of violating a potential donor's autonomy.

\section{METHODS}

\section{Data collection}

The target population was Hong Kong permanent residents aged between 18 and 60. With the required sample size being 784 to permit estimation of $95 \%$ CI with at the most a $3.5 \%$ margin of error, we conducted a public opinion survey attempting to interview 800 respondents. The interviews took place from 30 June to 14 July 2012 during the times of 08:00 to 22:30 on weekdays, and 15:00 to 22:30 on weekends, to improve the representativeness of respondents. The telephone numbers of households were generated by random-digit dialling such that every residential telephone number in Hong Kong had an equal probability of selection. Upon reaching a household, if more than one member was eligible, we invited the one whose next birthday was soonest to the survey date to participate. At least five different calls were made at different hours and days before we considered a number invalid. Verbal consent was obtained from the respondents and each interview took about $7 \mathrm{~min}$.

\section{Structure of the survey}

The survey was composed of four parts. In the first part, we asked the respondents whether they intend to donate their kidneys after death, whether they have registered as a donor and whether they have already discussed with their family. After a few questions about the present registration system and a brief introduction to brain death, we started the second part which concerned the likelihood that under the current explicit consent system the respondents would agree to donate the kidneys of a

\begin{tabular}{|c|c|c|}
\hline Variables & $\begin{array}{l}\text { Percentage } \\
\text { of } \\
\text { respondents }\end{array}$ & $\begin{array}{l}\text { Percentage of } \\
\text { Hong Kong } \\
\text { Population } \\
\text { Census } 2011\end{array}$ \\
\hline \multicolumn{3}{|l|}{ Men } \\
\hline $18-24$ & 7.11 & 6.13 \\
\hline $25-34$ & 5.61 & 9.00 \\
\hline $35-44$ & 6.98 & 9.38 \\
\hline $45-54$ & 10.2 & 12.0 \\
\hline $55-64$ & 8.35 & 9.13 \\
\hline \multicolumn{3}{|l|}{ Women } \\
\hline $18-24$ & 6.61 & 6.25 \\
\hline 25-34 & 6.11 & 12.5 \\
\hline $35-44$ & 15.5 & 13.0 \\
\hline $45-54$ & 17.8 & 13.5 \\
\hline $55-64$ & 15.7 & 9.13 \\
\hline \multicolumn{3}{|l|}{ Working status } \\
\hline Working & 66.46 & 65.50 \\
\hline Non-working & 33.54 & 34.50 \\
\hline \multicolumn{3}{|c|}{ Monthly household income } \\
\hline Below HKD10000 & 13.7 & 23.8 \\
\hline HKD10000-199999 & 22.7 & 23.8 \\
\hline HKD20000-299999 & 22.6 & 17.6 \\
\hline HKD30000-399999 & 12.1 & 11.4 \\
\hline HKD40000 or above & 26.2 & 23.5 \\
\hline \multicolumn{3}{|l|}{ Education } \\
\hline $\begin{array}{l}\text { No schooling or } \\
\text { kindergarten }\end{array}$ & 0.499 & $\mathrm{~N} / \mathrm{A}$ \\
\hline Primary & 8.60 & $\mathrm{~N} / \mathrm{A}$ \\
\hline Secondary & 48.4 & $\mathrm{~N} / \mathrm{A}$ \\
\hline Tertiary or above & 42.5 & $\mathrm{~N} / \mathrm{A}$ \\
\hline
\end{tabular}

deceased family member in different hypothetical situations (table 1). These included situations where the wish of the deceased member to donate has been previously communicated to the family, where the wish has been registered without any previous communication with the family, and where the wish is not known.

Before the third part started, we explained to the respondents the key features of the soft version of an opt-out system. Then, we asked the respondents, in the event that an opt-out system was implemented, whether they would be willing to donate their kidneys after death, whether they would plan to discuss their wish with the family, and whether they would opt out as a non-donor. The last part concerned the likelihood that under the proposed opt-out system the respondents would agree to donate the kidneys of a deceased family member in the event that the wish of the deceased member is not known.

Sample data were weighted to adjust for their difference from the general population with regard to age, gender and household income. The weights were developed based on the Hong Kong Population Census 2011 (table 2). 
Table 2 Intention to donate the kidneys of a deceased family member in different hypothetical situations ( $\mathrm{n}=802)$

\begin{tabular}{|c|c|c|c|c|c|}
\hline The scenario & Definitely (\%) & Likely (\%) & Not Likely (\%) & Definitely not (\%) & Unsure (\%) \\
\hline \multicolumn{6}{|c|}{ Wish of the deceased to donate has previously been communicated to the family member } \\
\hline & 67.9 & 26.9 & 1.58 & 1.25 & 2.45 \\
\hline \multicolumn{6}{|c|}{ Wish of the deceased to donate has previously NOT been communicated to the family member } \\
\hline \multicolumn{6}{|c|}{ Under the current explicit consent system } \\
\hline The deceased is a registered donor & 57.4 & 34.7 & 3.06 & 1.95 & 2.95 \\
\hline The deceased is not a registered donor & 21.1 & 30.1 & 23.5 & 13.5 & 11.9 \\
\hline \multicolumn{6}{|l|}{ Under the proposed opt-out system } \\
\hline The deceased has not opted out & 36.5 & 36.1 & 12.7 & 7.91 & 6.75 \\
\hline
\end{tabular}

\section{RESULTS}

A total of 1049 eligible respondents were reached and 802 completed the interview. The response rate was $76.4 \%$. Of the 802 respondents, $61.7 \%$ were women, $47.9 \%$ were aged less than $45,90.9 \%$ received education beyond primary school. After weighting, the sample had fewer women, younger ages and a lower monthly household income than the original sample. The data that we present below are all weighted. We have excluded 13 respondents from parts 1 and 3 of the survey because they considered themselves medically unfit as a kidney donor.

Under the current explicit consent system, $76.5 \%$ $(n=606)$ of respondents would like their family to donate their kidneys after death. Among the respondents, $15.7 \% \quad(\mathrm{n}=124)$ have registered their wish to donate their kidneys after death; $53.6 \% \quad(n=325)$ of those who intend to donate their kidneys after death have already conveyed or plan to convey their wish to their family at the time of the survey.

In the event that a family member has just died from a traffic accident and has previously conveyed to the respondents a wish to donate his/her kidneys after death; $94.7 \% \quad(n=760)$ of the respondents said that they would definitely or likely consent to the donation. If there has been no previous communication about the wish of the deceased, but the deceased is a registered donor, $92.0 \%$ would consent to the donation. The percentage dropped significantly to $51.2 \%$ (OR 0.0912 , $95 \%$ CI 0.0682 to 0.122 ) if that deceased family member has neither conveyed a clear wish nor registered as a donor (the wish is unknown).

Under the proposed opt-out system, $75.8 \%(\mathrm{n}=600)$ of respondents would like their family to donate their kidneys after death. Among those who would be willing to donate their kidneys after death, $69.3 \%$ either have already conveyed their wish to the family at the time of the survey or would plan to do so under the proposed system. Only $7.2 \% \quad(n=56.9)$ would opt out.

When the wish of the deceased is unknown, $72.6 \%$ $(n=583)$ of the respondents said that under the proposed opt-out system, they would definitely or likely consent to donating the kidneys of a deceased family member, significantly more than under the current explicit consent system (OR 2.53, 95\% CI 2.06 to 3.11). In the same hypothetical situation, while government payment of funeral expenses up to HKD50 000 (about US $\$ 6500$ ) would not significantly improve the chance of donation $(70.6 \%, \mathrm{n}=566$, $\mathrm{p}$ value $=0.346)$, provision of free lifelong medical services for four family members of the respondent's family would $(77 \%, \mathrm{n}=618$, OR 1.26 , 95\% CI 1.01 to 1.58 ).

\section{DISCUSSION}

In Hong Kong, a previous survey done in 1996 showed that $60.3 \%$ of Hong Kong people were willing to donate their kidneys after death, $85 \%$ were willing to donate a family member's organs if the wish of the deceased is known, and $41.1 \%$ were willing to do so if the wish of the deceased is not known. ${ }^{6}$ In 1997 , only $28 \%$ agreed with an opt-out system and $20 \%$ would opt out if it was implemented. ${ }^{7}$ In comparison, we found that nowadays a higher percentage of people are willing to donate their own kidneys $(76.5 \%)$ and would consent to donating the kidneys of a deceased family member $(94.7 \%$ when the wish of the deceased is known and $51.2 \%$ when the wish of the deceased is not known). We also found a much lower opt-out rate of $7.18 \%$ if an opt-out system is implemented. These differences can be accounted for by the change of attitudes, better education, increased awareness of organ shortage and improved publicity about organ donation, over the last decade or so, in Hong Kong. So far, there has been no study in Hong Kong aimed at estimating the impact of an opt-out system on the overall cadaveric kidney donation rate. The purported benefits of an opt-out system for Hong Kong remain speculative and so are the concerns about violating patients' autonomy.

\section{Impact of the proposed opt-out system}

We show that the benefits are not mere speculation. Under the current opt-in system, respondents are classified into five categories according to their registration status, their wish and communication with family members (figure 1). Under the proposed opt-out system, respondents are classified into four categories according to their intention to opt out, their wish and communication with family members (figure 2). We project the overall donation potential under the two systems by summation of the chance of donation for each category of 
Figure 1 Projected overall donation potential and chance of violating one's autonomy under the current system.

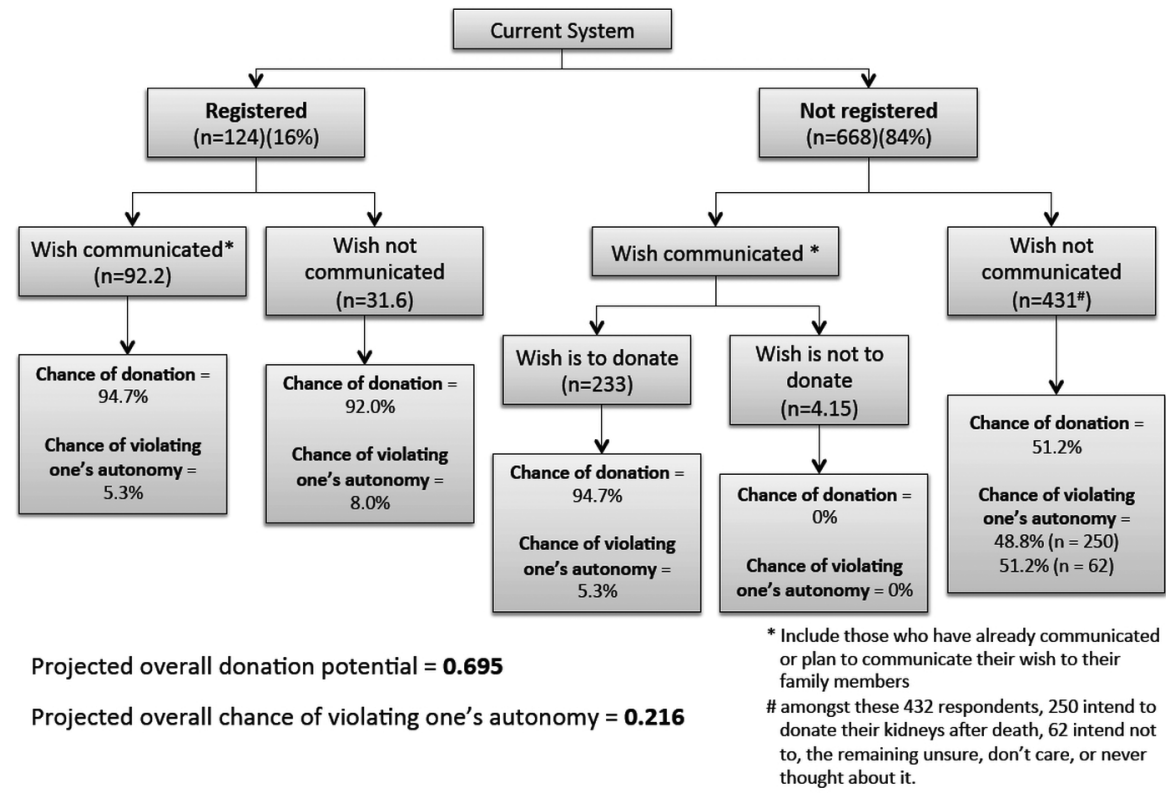

respondents. An opt-out system could significantly improve the overall donation potential from 0.695 $((92.2 \times 94.7 \%+31.6 \times 92 \%+233 \times 94.7 \%+431 \times 51.2 \%) / 802)$ to $0.771((417 \times 94.7 \%+297 \times 72.6 \%) / 802)($ OR $1.48,95 \%$ CI 1.18 to 1.84$)$. The increase is mainly attributable to a higher chance that people would plan to disclose their wish to the family and that they would consent to donating the kidneys of a family member in case the wish of the deceased is not known. A previous survey in Hong Kong found that people do not talk to the family about the wish to donate mainly because they have not thought about it or because they thought that it was too early to discuss the topic. ${ }^{6}$

The majority of people against an opt-out policy in Hong Kong thought that presuming consent would go against the wish of the deceased. ${ }^{7}$ We have proved it wrong, as an opt-out system would better respect people's right of self-determination rather than devalue it. We project the overall chance of violating one's autonomy under the two systems by summation of the chance of violation for each category of respondents. Our projected chance of violating the autonomy of a potential donor is much reduced from $0.216 \quad((92.2 \times 5.3 \%$ $+31.6 \times 8.0 \%+233 \times 5.3 \%+62 \times 51.2 \%+250 \times 48.8 \%) / 802)$ to $0.127 \quad((417 \times 5.3 \%+39 \times 72.6 \%+184 \times 27.4 \%) / 802) \quad(\mathrm{OR}$ $0.530,95 \%$ CI 0.406 to 0.692 ) by presuming consent. Indeed, one should be reminded that it is as important to protect the rights of those who do not wish to donate as to respect the wishes of those who do. In other words, one's autonomy will be violated if his or her kidneys are donated against his or her wish or if his or her kidneys are not donated when his or her wish is to do so. Having
Figure 2 Projected overall donation potential and chance of violating one's autonomy under the proposed system.

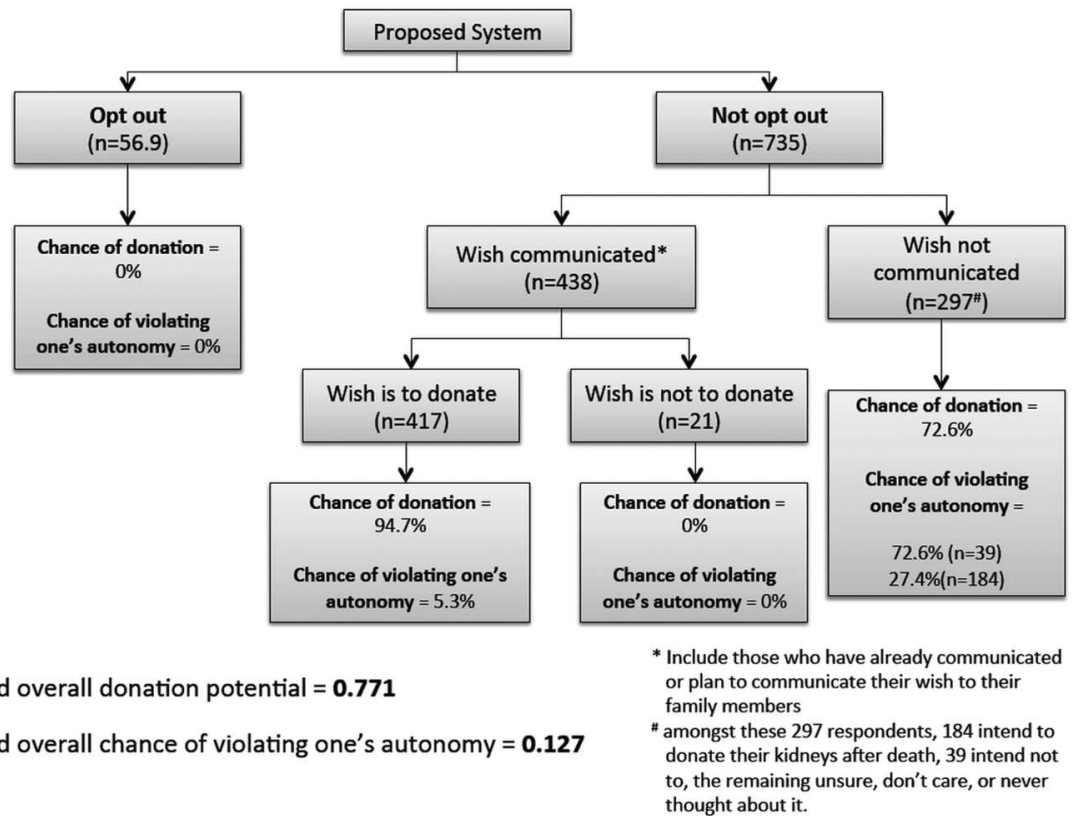


answered the critics' concerns about the impact of an opt-out system on the donation rate and patients' autonomy, we believe that it is time to initiate discussion about implementation of an opt-out policy among the policymakers and the general public in Hong Kong.

\section{Convenience of the registration system paramount}

Only $45.5 \%$ of those who are willing to donate their kidneys after death know how to register as a kidney donor in Hong Kong and agree that it is convenient to do so. Importantly, those who thought that it was convenient to register were seven times more likely to have registered (OR 10.1, 95\% CI 5.96 to 16.9). In order to protect the rights of those who do not wish to donate their kidneys, the opt-out registration system must be not only convenient but also perceived to be convenient. Adequate publicity is indispensable and the authors propose that people could be given additional opportunities to opt out when applying for an identity card, passport or driving licence.

\section{Limitations}

The generalisability of our findings to the broader population may be limited by our response rate $(76.4 \%)$ though it is comparable to that of other surveys (38.8$80.0 \%$ ) with similar methodology done in Hong Kong. ${ }^{8}$ Since our study was based on self-reported preferences and intentions, we may have underestimated or overestimated the overall donation potential and the overall chance of violating one's autonomy. In particular, when asked whether they would agree to donate the kidneys of a deceased family member under different hypothetical situations, and whether they would disclose to their family their wish to donate their kidneys after death, their ultimate action might be different from their response to our questions. Furthermore, the real chance that one may donate the kidneys of a deceased family member is not easily predictable, because it is usually a familial decision rather than an individual decision especially in the Chinese culture. Future studies would be necessary to verify the impact after actual implementation of the policy.

It is noteworthy that we made three assumptions in our estimation of the overall donation potential and overall chance of violating one's autonomy. To avoid asking respondents two strikingly similar questions, we have assumed that when the wish of the deceased to donate is known, the likelihood that one would consent to donation would be no different under both the systems. Second, due to technical constraints over the survey design, we have assumed that those who have communicated a wish to the family under the current explicit consent system would inform their family should they change their mind under the proposed opt-out system. Nonetheless, only $0.362 \%$ of respondents said they would change their mind. We have also assumed that should one's wish not to donate be known, the chance of donation under both systems would be zero.
As only $0.126 \%$ of respondents have conveyed a wish not to donate their kidneys under the current system, and only $2.65 \%$ would do so under the proposed system, even if the chance of donation in this scenario is taken to be $8.9 \%{ }^{6}$ which a previous survey in Hong Kong has found, our estimation would be the same, taking only two significant figures.

\section{CONCLUSIONS}

Despite concerns that presumed consent might undermine patients' autonomy, such worry was without support from empirical data. Our projected findings that a switch to an opt-out system would likely result in the wishes of more people being followed and raise the overall cadaveric kidney donation rate should prompt policymakers in Hong Kong to move ahead in the direction of saving people's lives. Over and above an opt-out policy, we should further explore the impact of offering incentives, and ways to improve living donation rate. In light of the reluctance to switch to an opt-out system in the $\mathrm{UK}^{9}$ and US, ${ }^{10}$ a similar survey in their own populations may be useful with a view to refuting the speculative claim that an opt-out system has the potential to impact negatively on the donation rate and patients' autonomy.

Acknowledgements We would like to thank CN Chan, G Lai and Kelvin for their outstanding help in data analysis.

Contributors TKC, BJC and GLT conceived the idea of the study and were responsible for the design of the study. TKC and BJC were responsible for undertaking for the data analysis and produced the tables and graphs. TKC and GLT provided input into the data analysis. The initial draft of the manuscript was prepared by TKC and then circulated repeatedly among all authors for critical revision. TKC was responsible for the acquisition of the data and TKC, BJC and GLT contributed to the interpretation of the results.

Funding This study was funded by the Seed Development Grant provided by the University of Hong Kong.

Competing interests None.

Ethical approval This study was approved by the Institutional Review Board of the University of Hong Kong/Hospital Authority Hong Kong West Cluster.

Provenance and peer review Not commissioned; externally peer reviewed.

Data sharing statement Full results of the survey are available from TKC at theo@hku.hk.

\section{REFERENCES}

1. Gimbel RW, Strosberg MA, Lehrman SE, et al. Presumed consent and other predictors of cadaveric organ donation in Europe. Prog Transplant 2003;13:17-23.

2. Abadie A, Gay S. The impact of presumed consent legislation on cadaveric organ donation: a cross-country study. J Health Econ 2006;25:599-620.

3. Wright $L$. Is presumed consent the answer to organ shortages? No. BMJ 2007;334:1089.

4. Rithalia A, McDaid C, Suekarran S, et al. Impact of presumed consent for organ donation on donation rates: a systematic review. BMJ 2009;338:a3162.

5. Department of Health, UK. Organs for transplants: a report from the Organ Donation Taskforce 2008. http://www.dh.gov.uk/en/ Publicationsandstatistics/Publications/PublicationsPolicyAndGuidance/ DH_082122 (accessed 2 Aug 2012).

6. Yeung I, Kong SH, Lee J. Attitudes towards organ donation in Hong Kong. Soc Sci Med 2000;50:1643-54. 
7. Li PK, Lin CK, Lam PK, et al. Attitudes about organ and tissue donation among the general public and blood donors in Hong Kong. Prog Transplant 2001;11:98-103.

8. The range of response rates for the survey entitled 'People's Satisfaction with the HKSAR Government' done every month from July 1997 until now by the University of Hong Kong Public Opinion Programme. http://hkupop.hku.hk/english/popexpress/sargperf/sarg/ poll/contactinfo.html (accessed 2 Aug 2012).
9. Organ Donation Taskforce, UK. The potential impact of an opt out system for organ donation in the UK: and independent report by the Organ Donation Taskforce. 2008. http://www.dh.gov.uk/en/

Publicationsandstatistics/Publications/

PublicationsPolicyAndGuidance/DH_090312 (accessed 3 Aug 2012).

10. Bard JS. Lack of political will and public trust dooms presumed consent. Am J Bioeth 2012;12:44-6. 